\title{
Birds of a feather
}

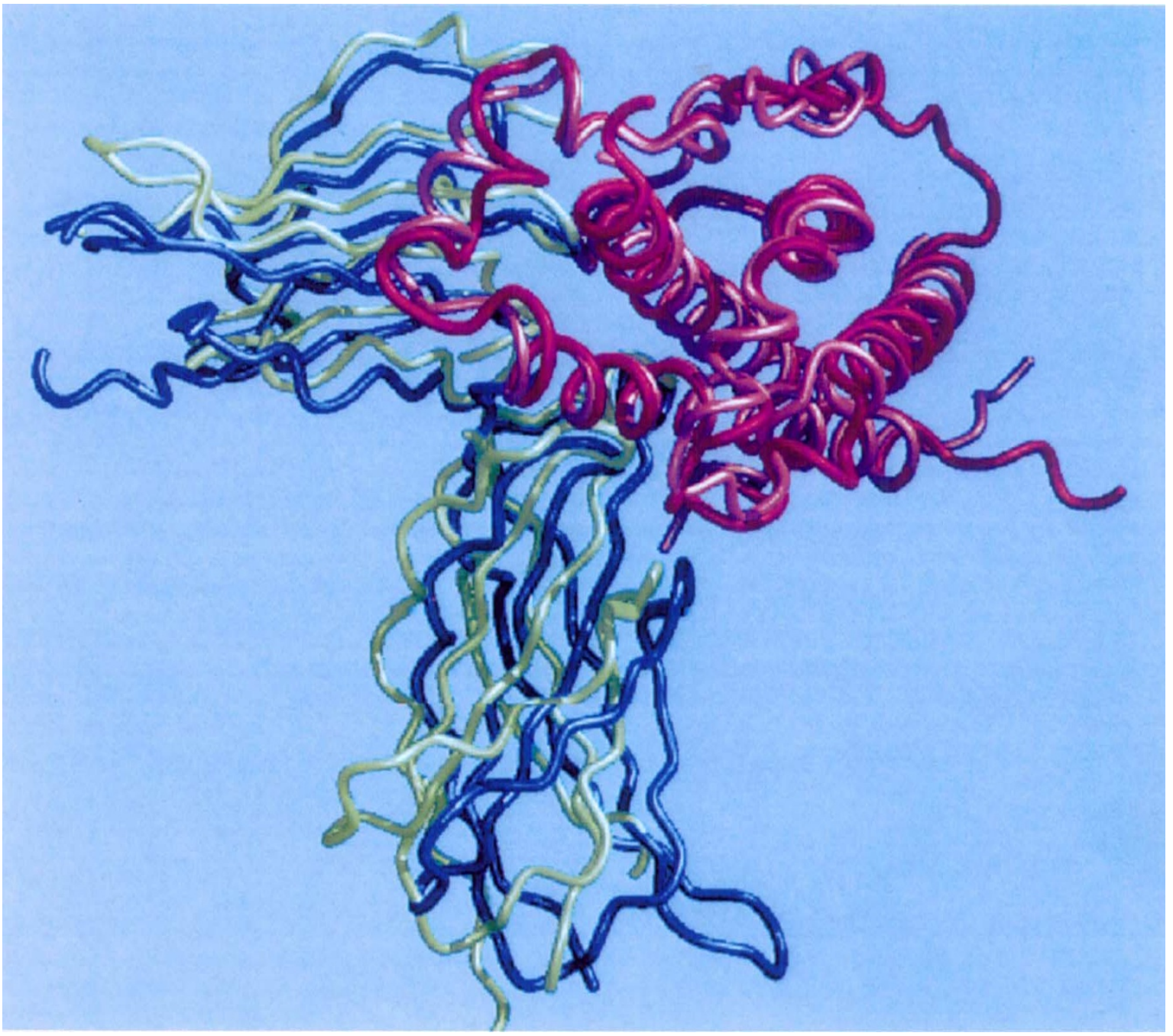

Both growth hormone and prolactin are small peptide hormones produced by the pituitary gland which control a variety of physiological processes. They act by binding to specific receptors on the cell surface causing them to dimerize which in turn results in activation of a phosphorylation-cascade involving a number of tyrosine kinases. Growth hormone can bind and activate its own receptor and also bind the receptor for prolactin. Prolactin, on the other hand, cannot bind growth hormone receptor while growth hormone does not induce the heterodimerization of a growth hormone and a prolactin receptor. Some of the structural considerations underlying the promiscuous interactions of growth hormone have now been elucidated with the determination of the 1:1 complex between growth hormone and the prolactin receptor (Somers, W., Ultsch, M., De Vos, A.M. \& Kossiakoff, A.A. Nature in the press) an intermediate in the formation of the active dimer.

The prolactin and growth hormone receptor share $28 \%$ sequence homology and their structures are very similar (the picture shows an overlay of the growth hormone(red)-prolactin receptor(blue) and growth hormone(magenta)-growth hormone receptor(green) complexes, reproduced with permission). The hormone-binding cleft of both receptors is formed by two modules homologous to the tandem repeats of fibronectin. The modules in the two receptors are essentially identical and bind growth hormone in the same fashion. The major differences between the two receptors are in the relative orientations of these two modules.

The ability of the two different receptors to bind growth hormone while discriminating for prolactin is a testament to the flexibility of the fibronectin-like domains, and comparison of the fine detail of these hormone-receptor complexes reveals the structural basis for this flexibility. The differences in the orientations of the domains appear to be the root cause for the absence of prolactin receptorgrowth hormone receptor heterodimers. While homodimerization is the natural result of hormone binding, steric clashes between parts of the hormone-binding domains far from the specific hormonebinding site prevent formation of the non-productive, 'mixed', ternary complex. 